\title{
Influence of Weld Toe Radii on Fatigue Life Prediction
}

\author{
Kin Shun Tsang ${ }^{1 .}{ }^{*}$ John H. L. Pang ${ }^{1}$, Hsin Jen Hoh $^{1}$ \\ ${ }^{1}$ School of Mechanical \& Aerospace Engineering, Nanyang Technological University, \\ 50 Nanyang Avenue, Singapore 639798, Singapore
}

\begin{abstract}
A study was carried out to investigate the influence of the weld toe radii on the fatigue strength of butt welded joints loaded in bending and tension. Fatigue analysis starting from weld toe cracks in marine and offshore welded pipe specimens were conducted using cut-out four-point bend fatigue test specimens. Fatigue life can be enhanced by reducing the local stress concentration generated by weld toe radius effects. This study investigated the effect of different weld toe radii on the stress intensity factor at the region of the weld toe through Finite Element Analysis (FEA). FEA was used to model a butt welded steel plate extracted from a pipe subject to tension and four-point bend loading. Semi-elliptical surface (SESC) cracks were modeled at the weld toe region with different SESC crack depth and surface crack length. Four weld toe radii and two modes of loading were investigated. The stress intensity factors, weald toe magnification factors, or $\mathrm{M}_{\mathrm{kc}}$ and $\mathrm{M}_{\mathrm{ka}}$ are reported and used for fatigue life prediction.
\end{abstract}

\section{Introduction}

With the complex nature of dealing with welds in marine and offshore structures, it is essential to understand the fatigue life prediction research of welded joints better. The fatigue life of welded joints is dependent on the weld toe radius effects on local stress concentration on fatigue life of welded joints in addition to the global structural stress concentration effect of the welded joint geometry.

The fatigue life of welded structures with initial weld toe cracks can be predicted by the linear elastic fracture mechanics approach covered in BS7910 [1]. Fatigue crack growth prediction can be made using the stress intensity factor range $(\Delta K)$ and crack propagation rate $(\mathrm{d} a / \mathrm{d} N)$ [2] through a Paris law [3]. The Stress Intensity Factor (SIF) solutions can be determined from finite element analysis [4]. The ratio of the SIF of a plate with welded attachment as compared to the SIF of a plain plate is defined as the weld magnification $\left(M_{k}\right)$ factor [5]. $M_{k}$ factors are influenced by the size of the welded attachment, as well as the size and depth of the weld toe crack.

Niu and Glinka [6] employed weight function methods that included weld toe radius as a parameter in assessing the stress intensity factor of welded joints. However, this study only allows for the assessment of stress intensity factors for the deepest point of the semielliptical crack, with no mention of the effect of the weld toe radius on the crack ends. Improving on $\mathrm{Niu}$ and Glinka's weight function, Brennan et al. [7] conducted a study to generate parametric equations for T-butt weld toe stress intensity factor, which took into account the weld toe radius effect, among other factors. However, the methodology employed the usage of two- dimensional finite element analysis to evaluate the stress distribution caused by the opening of the crack, before using that as an input into a weight function solution for determining stress intensity factors. While these equations are validated against a wide spectrum of values, the usage of two-dimensional finite element analysis may not be as accurate. Studies by Zhang et al. [8] also concluded that the crack growth rate will be overestimated if two-dimensional $\mathrm{M}_{\mathrm{k}}$ solutions were used instead of three-dimensional solutions.

In BS7910 [1], in the section that deals with surface cracks, it is found that $\mathrm{M}_{\mathrm{k}}$ is a function of the crack depth, $a$, overall width of the attachment measured from left weld toe to right weld toe, and the thickness of the plate, t. Figure 1 shows a schematic of our four-point bend test specimen extracted from an offshore pipe. In this test configuration, multiple weld toe cracks will be initiated at the butt weld-to-parent metal weld toe region at the bottom weld toe sites.

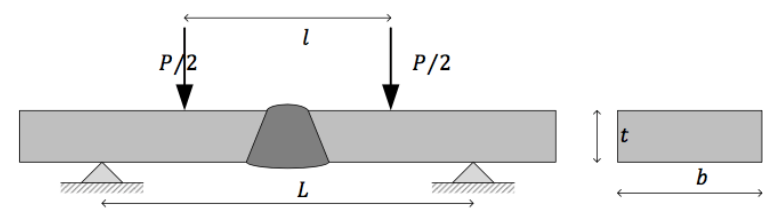

Figure 1. Butt weld, used in four point bend loading.

In BS7910, the Mk factors for weld toe cracks is reported for a specific weld toe radii citing the reference by Bowness and Lee [9]. The effect of the weld toe radii on the stress intensity factor was not the focus of the study. Hence, there is a need to investigate the effect of weld toe radii on the magnification factor using threedimensional finite element analysis.

Corresponding author: kstsang@ntu.edu.sg 
This work will investigate the influence of the weld toe radii on the $\mathrm{M}_{\mathrm{kc}}$ and $\mathrm{M}_{\mathrm{ka}}$ factors for butt welded joints loaded in tension and bending. The derived $\mathrm{M}_{\mathrm{k}}$ factors are then used to predict the fatigue life of a fourpoint bend fatigue test specimen result taking into account a sharp weld toe radius and a weld toe radius of $1.0 \mathrm{~mm}$ in the fatigue life prediction example. ABAQUS was used to model semi-elliptical surface crack (SESC) in a steel plate and the model is then modified to develop the butt weld geometry over it to determine the $\mathrm{M}_{\mathrm{kc}}$ and $\mathrm{M}_{\mathrm{ka}}$ factors. Different semi-elliptical surface crack geometries $(a, c)$ were modeled at the weld toe. Four weld toe radii were investigated for sharp toe with zero radius, and 3 radii sizes of $0.1,0.5$ and $1.0 \mathrm{~mm}$ respectively. The FEA work looks at two modes of loading for tension and four-point bending.

\section{Weld toe crack model}

This section describes the methodology and modelling procedure of the weld toe crack model.

\subsection{Methodology}

XFEM was used in this study to produce a finite element model of the crack, to investigate the effect of different weld toe radii on the $\mathrm{M}_{\mathrm{k}}$ factors. A parametric study using plane butt joint geometry was carried out using the ABAQUS. Figure 2 shows the plain plate and plate with attachment that was modelled.

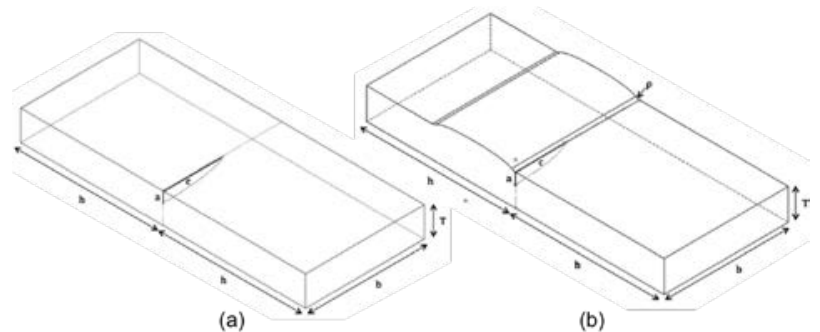

Figure 2. a) Plain plate b) Plate with butt weld geometry.

The analysis matrix covered is shown in Table 1.

Table 1. Matrix of model parametered investigated.

\begin{tabular}{|c|c|c|}
\hline $\boldsymbol{a} / \boldsymbol{T}$ & $\boldsymbol{a} / \boldsymbol{c}$ & $\boldsymbol{\rho} \mathbf{( m m )}$ \\
\hline 0.05 & $0.1,0.5,1.0$ & $0,0.1,0.5,1.0$ \\
\hline 0.1 & $0.1,0.5,1.0$ & $0,0.1,0.5,1.0$ \\
\hline 0.5 & $0.1,0.5,1.0$ & $0,0.1,0.5,1.0$ \\
\hline
\end{tabular}

Table 1 lists the different parameters that will be used to compare the effect of the weld toe radii. The base value of $\rho=0$ is used to compare the effect of a sharp weld toe compared to a weld toe with different weld toe radii, $\rho$ values of $0.1,0.5$ and $1.0 \mathrm{~mm}$. Two analyses was carried out for applied tension (membrane) loading, and for four-point bend loading.

\subsection{Modelling Procedure}

A 3D half model was used, such that the crack was symmetrical about the $\mathrm{x}$ axis, due to the symmetry. At the area nearest to the crack, the model was partitioned according to the shape of the crack, with a finer mesh. The mesh then became coarser progressively away from the semi-elliptical surface crack. This allowed for a faster computational time and accuracy was calibrated with SIF solutions reported by Newman and Raju [12]. .

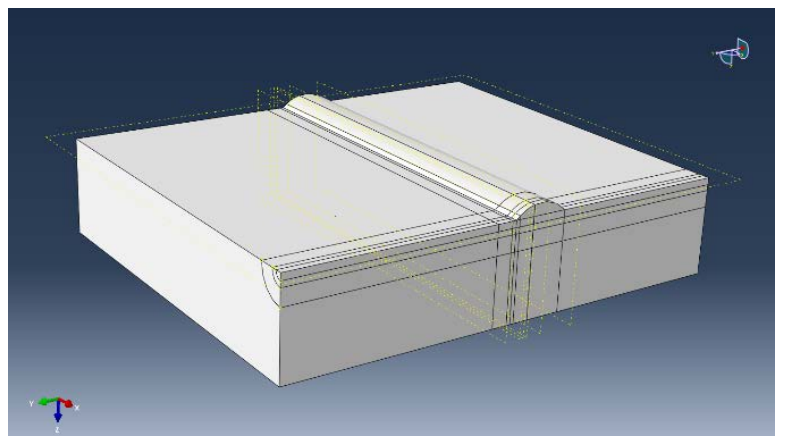

a)

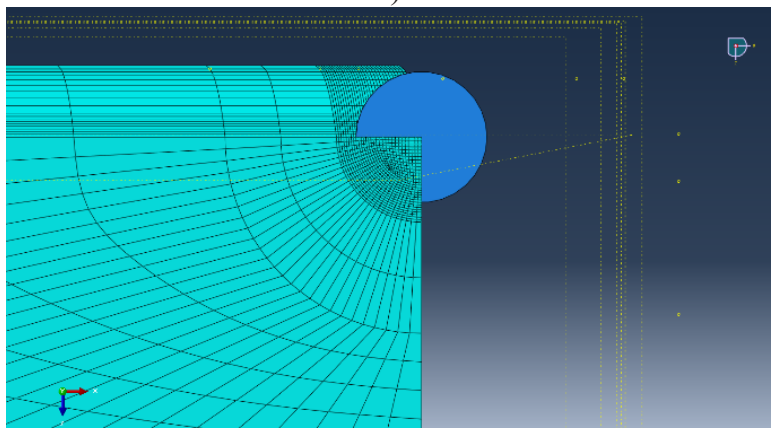

b)

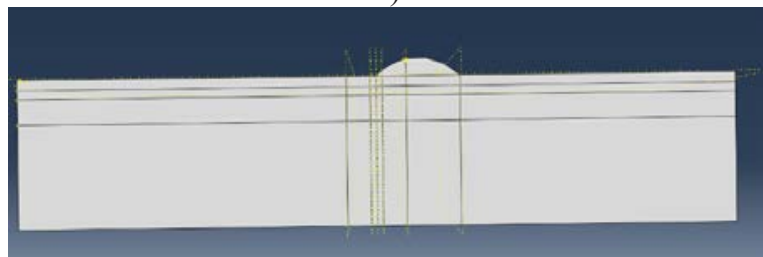

c)

Figure 3. a) Partition of the model ; b) Sample mesh of the model near the crack represented by the circle; c) Profile of the plate with butt weld feature with a sharp weld toe, $\rho=0$.

The Elastic Modulus of $210 \mathrm{GPa}$ and a Poisson's ratio of 0.3 for the steel material was used. The model is for a four-point bend fatigue specimens reported by Pang et al. [10]. The dimensions of the steel plate are shown in Table 2.

Table 2. Dimensions of the steel plate.

\begin{tabular}{|c|c|}
\hline Dimension & Length \\
\hline Length of steel plate $(2 h)$ & $240 \mathrm{~mm}$ \\
\hline Width of steel plate $(2 b)$ & $200 \mathrm{~mm}$ \\
\hline Height of steel plate $(\mathrm{T})$ & $25 \mathrm{~mm}$ \\
\hline Height of weld attachment $\left(h_{\text {att }}\right)$ & $3 \mathrm{~mm}$ \\
\hline Length of weld attachment $(L)$ & $14 \mathrm{~mm}$ \\
\hline
\end{tabular}

\subsubsection{Tensile Load}


For tensile loading, a load was applied on one end of the model. A fixed displacement boundary condition was applied on the opposite face from which the load was applied.

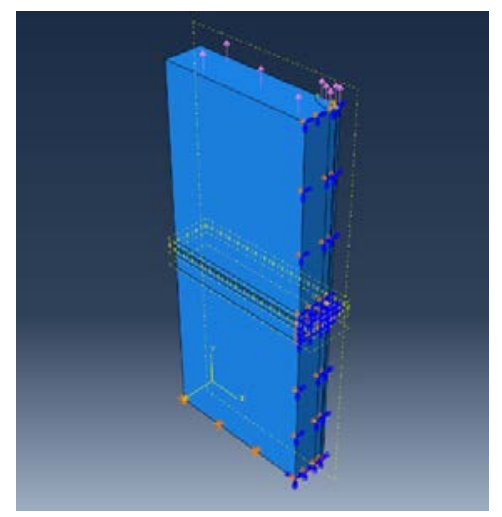

Figure 4. Sample load on a model undergoing tensile loading.

As a half-crack model was used, a boundary condition to account for symmetrical conditions was employed.

\subsubsection{Bending Load}

The bending load is based on the four-point bend loading conditions (Figure 1).

The bending stress applied and bending moment of relationship is given in equation 1 .

$$
\Delta \sigma=-\frac{6 M_{z}}{b T^{2}}
$$

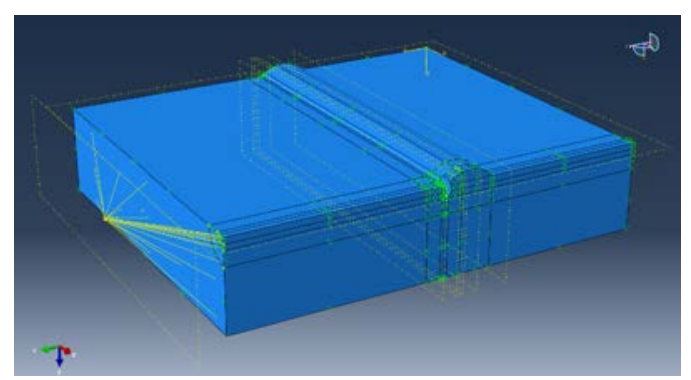

Figure 5. Four point bend loading illustration.

To obtain the SIF value along the crack front, 8 contour integrals were used. Only the $3^{\text {rd }}$ to $7^{\text {th }}$ integral are used in evaluating the average SIF value at each location for reliable results compared to Newman's reported results [11].

\section{Effect of Weld Toe Radius on SIF}

This section describes the results of the simulation.

\subsection{Tensile Loading}

To observe the effect of the weld toe radii on the stress intensity factor on tensile loading, the results will be separated into that at the crack ends, as well as that at the deepest point of the crack, which will be discussed in the next section.

\subsubsection{Crack Ends}

The results are sorted according to its crack aspect ratio $(\mathrm{a} / \mathrm{c})$. The result from each simulation is given in the table below:

Table 3. $\mathrm{M}_{\mathrm{k}, \mathrm{c}}$ values for crack ends under tensile load.

\begin{tabular}{|c|c|c|c|c|c|}
\hline \multirow{2}{*}{$\boldsymbol{a} / \boldsymbol{c}$} & $\boldsymbol{a} / \boldsymbol{T}$ & \multicolumn{4}{|c|}{$\mathbf{M}_{\mathbf{k , c}}$} \\
\cline { 2 - 6 } & & $\boldsymbol{\rho}=\mathbf{0}$ & $\boldsymbol{\rho}=\mathbf{0 . 1}$ & $\boldsymbol{\rho}=\mathbf{0 . 5}$ & $\boldsymbol{\rho}=\mathbf{1 . 0}$ \\
\hline \multirow{3}{*}{1.0} & 0.05 & 1.6802499 & 1.6037761 & 1.4578918 & 1.4054604 \\
\cline { 2 - 6 } & 0.1 & 1.4218269 & 1.4056439 & 1.3105523 & 1.2595960 \\
\cline { 2 - 6 } & 0.5 & 1.1658519 & 1.1744366 & 1.1532133 & 1.1280553 \\
\hline 0.5 & 0.05 & 1.6862815 & 1.6341801 & 1.5023521 & 1.4529703 \\
\cline { 2 - 6 } & 0.1 & 1.4416781 & 1.4229711 & 1.3383768 & 1.2887207 \\
\cline { 2 - 6 } & 0.5 & 1.1404797 & 1.1442619 & 1.1319429 & 1.132051 \\
\hline 0.25 & 0.05 & 1.8243668 & 1.7622910 & 1.5815262 & 1.4937924 \\
\cline { 2 - 6 } & 0.1 & 1.5572065 & 1.5350833 & 1.4345385 & 1.3698200 \\
\cline { 2 - 6 } & 0.5 & 1.2010747 & 1.2045454 & 1.1945812 & 1.1628974 \\
\hline
\end{tabular}

The $\mathrm{M}_{\mathrm{k}}$ results are plotted into graphical form according to the crack depth ratio $(a / T)$, crack aspect ratio $(a / c)$ and crack radii $(\rho)$.

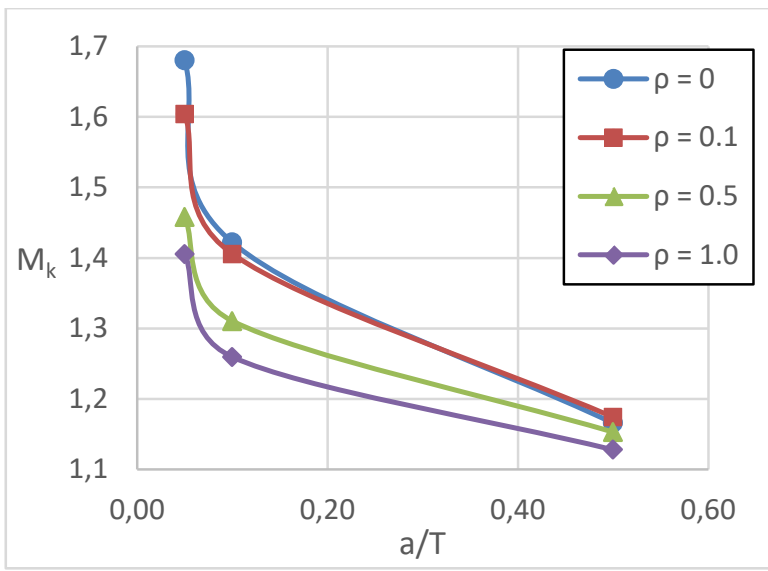

a)

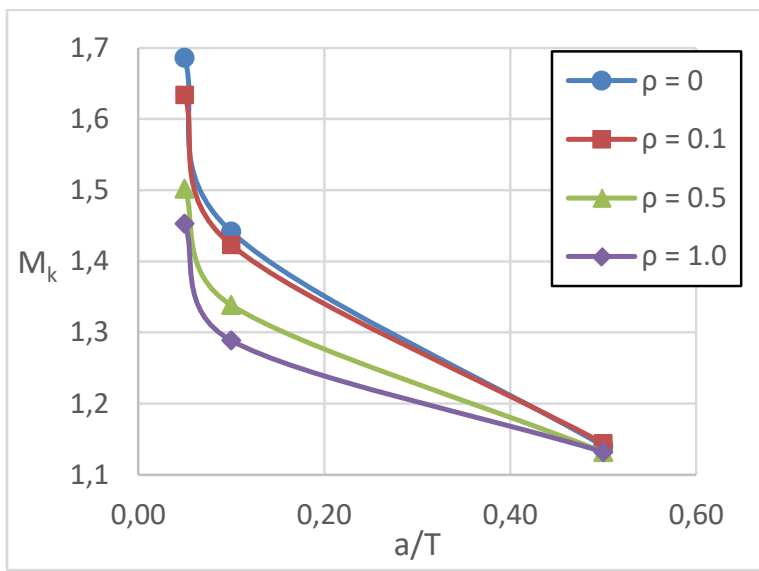

b) 


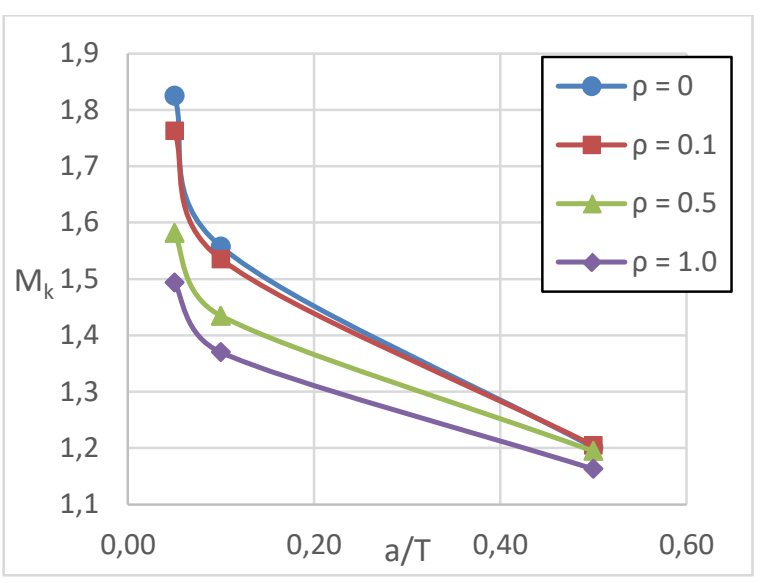

c)

Figure 6. Plot of $\mathrm{M}_{\mathrm{k}, \mathrm{c}}$ values for crack ends under tensile loading: a) $\mathrm{a} / \mathrm{c}=1.0 ; \mathrm{b}$ ) $\mathrm{a} / \mathrm{c}=0.5 ; \mathrm{c}$ ) $\mathrm{a} / \mathrm{c}=0.25$.

From the graphs (in Figure 6), it can be seen that with an increasing weld toe radius, the $\mathrm{M}_{\mathrm{k}, \mathrm{c}}$ value at the crack ends decreases. This is especially true for smaller cracks. The decrease in $\mathrm{M}_{\mathrm{k}, \mathrm{c}}$ factor is as much as $16.3 \%$ in the case of $a / c=1, a / T=0.05$. From this set of results, it can be inferred that the weld toe radius does help in reducing the stress intensity factor at the weld toe for small cracks.

\subsubsection{Deepest Point of Crack}

Similarly, the data will be sorted according to its crack aspect ratio $(a / c)$ to allow for meaningful discussion of the results. The results from each simulation are given in the table and Figure 7 below:

Table 4. $M_{k, a}$ values for deepest point of crack under tensile

load.

\begin{tabular}{|c|c|c|c|c|c|}
\hline \multirow{2}{*}{$\boldsymbol{a} / \boldsymbol{c}$} & $\boldsymbol{a} / \boldsymbol{T}$ & \multicolumn{4}{|c|}{$\mathbf{M}_{\mathbf{k , a}}$} \\
\cline { 2 - 6 } & & $\boldsymbol{\rho}=\mathbf{0}$ & $\boldsymbol{\rho}=\mathbf{0 . 1}$ & $\boldsymbol{\rho}=\mathbf{0 . 5}$ & $\boldsymbol{\rho}=\mathbf{1 . 0}$ \\
\hline \multirow{3}{*}{1.0} & 0.05 & 1.0367309 & 1.0163758 & 1.0264768 & 1.0506581 \\
\cline { 2 - 6 } & 0.1 & 0.9504995 & 0.9386921 & 0.9430820 & 0.9557977 \\
\cline { 2 - 6 } & 0.5 & 0.9617063 & 0.9614247 & 0.9622694 & 0.9655075 \\
\hline 0.5 & 0.05 & 1.0481380 & 1.0337193 & 1.0388283 & 1.0617620 \\
\cline { 2 - 6 } & 0.1 & 0.9666330 & 0.9656253 & 0.9677527 & 0.9705520 \\
\cline { 2 - 6 } & 0.5 & 1.0107441 & 1.0107441 & 1.0115259 & 1.0058580 \\
\hline 0.25 & 0.05 & 1.0485092 & 1.0479340 & 1.0511935 & 1.0528233 \\
\cline { 2 - 6 } & 0.1 & 1.0047072 & 1.0065705 & 1.0075512 & 1.0096106 \\
\cline { 2 - 6 } & 0.5 & 0.9809211 & 0.9844022 & 0.9848038 & 0.9825947 \\
\hline
\end{tabular}

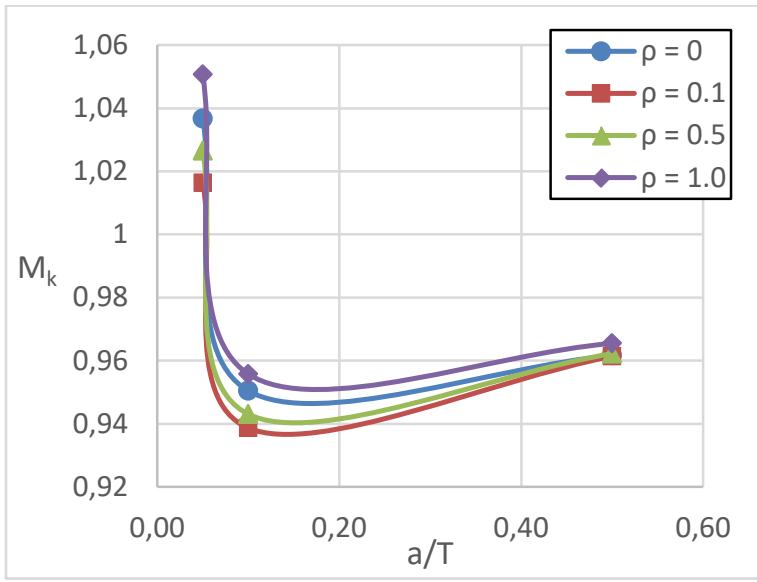

a)

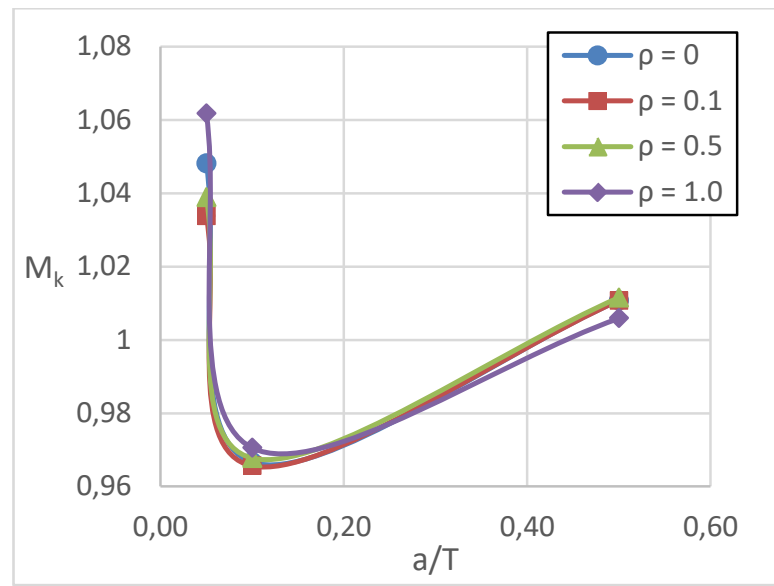

b)

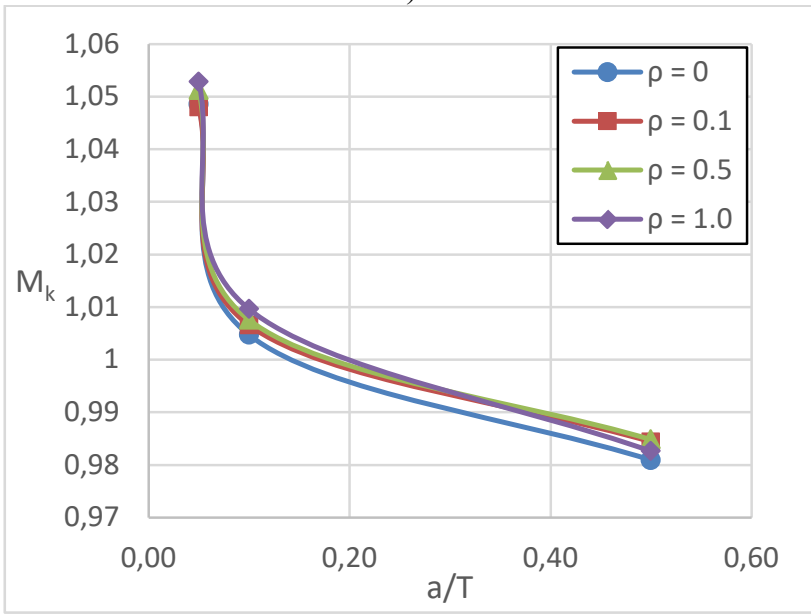

c)

Figure 7. Plot of $\mathrm{M}_{\mathrm{k}, \mathrm{a}}$ values for deepest point of crack under tensile loading: a) $\mathrm{a} / \mathrm{c}=1.0 ; \mathrm{b}$ ) $\mathrm{a} / \mathrm{c}=0.5$; c) $\mathrm{a} / \mathrm{c}=0.25$.

For the deepest point of the crack under tensile loading, there is little effect of the weld toe radius on the $\mathrm{M}_{\mathrm{k}, \mathrm{a}}$ values. As can be seen from Figure 7 , for each $a / T$ parameter, the $\mathrm{M}_{\mathrm{k}, \mathrm{a}}$ values are clustered closely together with little variation. The deepest point of the crack is far from the weld toe, and the weld toe radius has little to no effect on the $\mathrm{M}_{\mathrm{k}, \mathrm{a}}$ values.

\subsection{Four Point Bend Loading}

This section will discuss the effect of weld toe radii on the Mk factor subject to four-point bend loading.

\subsubsection{Crack Ends}

The results are given in Table 5 and Figure 8.

Table 5. $\mathrm{M}_{\mathrm{k}, \mathrm{c}}$ values for crack ends under four point bend load.

\begin{tabular}{|c|c|c|c|c|c|}
\hline \multirow{2}{*}{$\boldsymbol{a} / \boldsymbol{c}$} & $\boldsymbol{a} / \boldsymbol{T}$ & \multicolumn{4}{|c|}{$\mathbf{M}_{\mathbf{k}}$} \\
\cline { 2 - 6 } & & $\boldsymbol{\rho}=\mathbf{0}$ & $\boldsymbol{\rho}=\mathbf{0 . 1}$ & $\boldsymbol{\rho}=\mathbf{0 . 5}$ & $\boldsymbol{\rho}=\mathbf{1 . 0}$ \\
\hline \multirow{3}{*}{1.0} & 0.05 & 1.7187543 & 1.7020807 & 1.5376877 & 1.4474300 \\
\cline { 2 - 6 } & 0.1 & 1.4603804 & 1.4189133 & 1.3266730 & 1.2809634 \\
\cline { 2 - 6 } & 0.5 & 1.1777423 & 1.1971851 & 1.1606210 & 1.1385664 \\
\hline 0.5 & 0.05 & 1.6860383 & 1.6343649 & 1.4999299 & 1.4390141 \\
\cline { 2 - 6 } & 0.1 & 1.4847930 & 1.4604336 & 1.3690509 & 1.3114615 \\
\cline { 2 - 6 } & 0.5 & 1.1545724 & 1.1575397 & 1.1447261 & 1.1273266 \\
\hline 0.25 & 0.05 & 1.7963111 & 1.7310344 & 1.5587810 & 1.4564554 \\
\cline { 2 - 6 } & 0.1 & 1.6251058 & 1.5852956 & 1.4758597 & 1.4070811 \\
\cline { 2 - 6 } & 0.5 & 1.2156430 & 1.2462131 & 1.1914073 & 1.2232167 \\
\hline
\end{tabular}


The results were plotted in graphical form according to the crack aspect ratios $(\mathrm{a} / \mathrm{c})$.

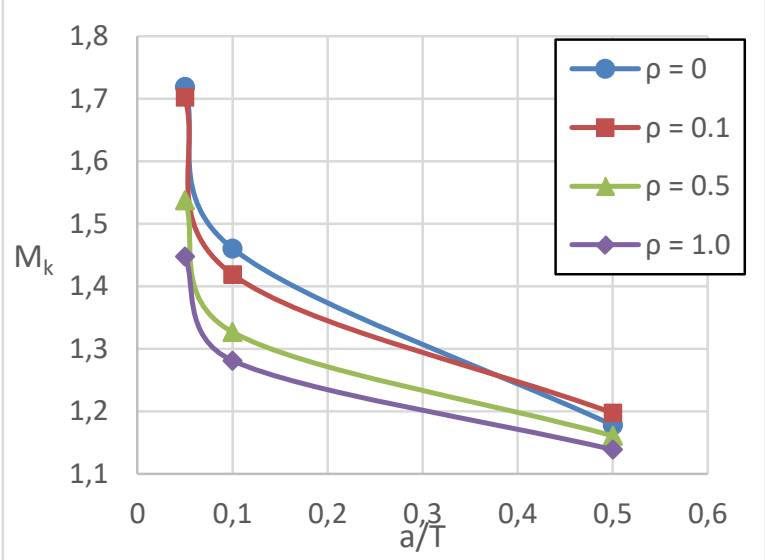

a)

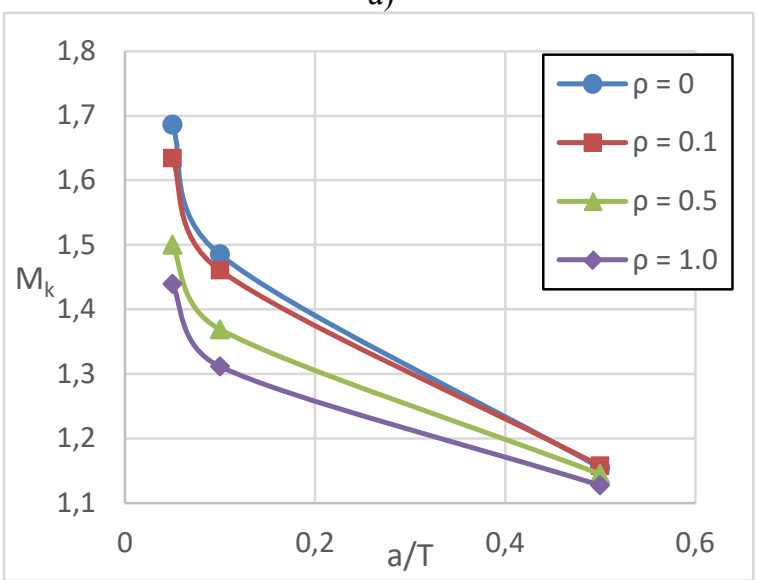

b)

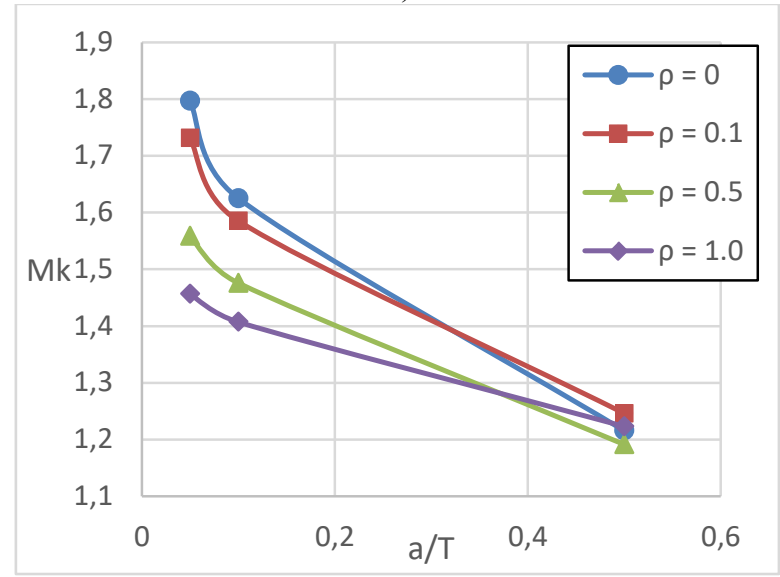

c)

Figure 8. Plot of $\mathrm{M}_{\mathrm{k}, \mathrm{c}}$ values for crack under four point bend loading: a) $\mathrm{a} / \mathrm{c}=1.0$; b) $\mathrm{a} / \mathrm{c}=0.5$; c) $\mathrm{a} / \mathrm{c}=0.25$.

The $\mathrm{M}_{\mathrm{k}, \mathrm{c}}$ values of the crack ends subjected to fourpoint bend loading is similar to that of the crack ends subjected to tensile loading. There is a decreasing trend of $\mathrm{M}_{\mathrm{k}, \mathrm{c}}$ values with increasing weld toe radius, for smaller cracks. For bending, the decrease in $\mathrm{M}_{\mathrm{k}, \mathrm{c}}$ factor is as much as $18.9 \%$ in the case of $a / c=0.25, a / T=0.05$.

For larger cracks $(a / T=0.5)$, the weld toe radius plays a limited role in reducing the stress intensity factor.

\subsubsection{Deepest Point of Crack}

The results are given in Table 6 and Figure 9.

Table 6. $\mathrm{M}_{\mathrm{k}, \mathrm{a}}$ values for deepest point of crack for bend load.

\begin{tabular}{|c|c|c|c|c|c|}
\hline \multirow{2}{*}{$\boldsymbol{a} / \boldsymbol{c}$} & $\boldsymbol{a} / \boldsymbol{T}$ & \multicolumn{4}{|c|}{$\mathbf{M}_{\mathrm{k,a}}$} \\
\cline { 3 - 6 } & & $\boldsymbol{\rho}=\mathbf{0}$ & $\boldsymbol{\rho}=\mathbf{0 . 1}$ & $\boldsymbol{\rho}=\mathbf{0 . 5}$ & $\boldsymbol{\rho}=\mathbf{1 . 0}$ \\
\hline \multirow{3}{*}{1.0} & 0.05 & 1.2029432 & 1.2465108 & 1.2604977 & 1.2350739 \\
\cline { 2 - 6 } & 0.1 & 1.0101311 & 1.0053868 & 1.0129676 & 1.0289566 \\
\cline { 2 - 6 } & 0.5 & 0.8951208 & 0.9038336 & 0.8870623 & 0.8911142 \\
\hline 0.5 & 0.05 & 1.1131830 & 1.1022148 & 1.1065656 & 1.1247377 \\
\cline { 2 - 6 } & 0.1 & 0.9807743 & 0.9811518 & 0.9839140 & 0.9869814 \\
\cline { 2 - 6 } & 0.5 & 0.9504534 & 0.9502521 & 0.9516799 & 0.9535723 \\
\hline 0.25 & 0.05 & 1.0407916 & 1.0628861 & 1.0648652 & 1.0664868 \\
\cline { 2 - 6 } & 0.1 & 1.0246193 & 1.0474590 & 1.0484325 & 1.0498063 \\
\cline { 2 - 6 } & 0.5 & 0.9751157 & 0.9923764 & 0.9631603 & 0.9938617 \\
\hline
\end{tabular}

The results are shown in graphical form according to the crack aspect ratios $(a / c)$.

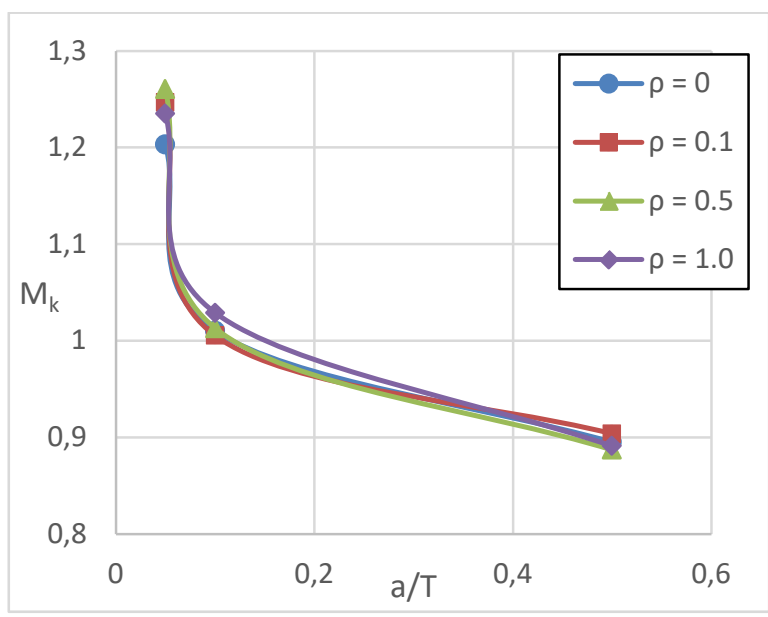

a)

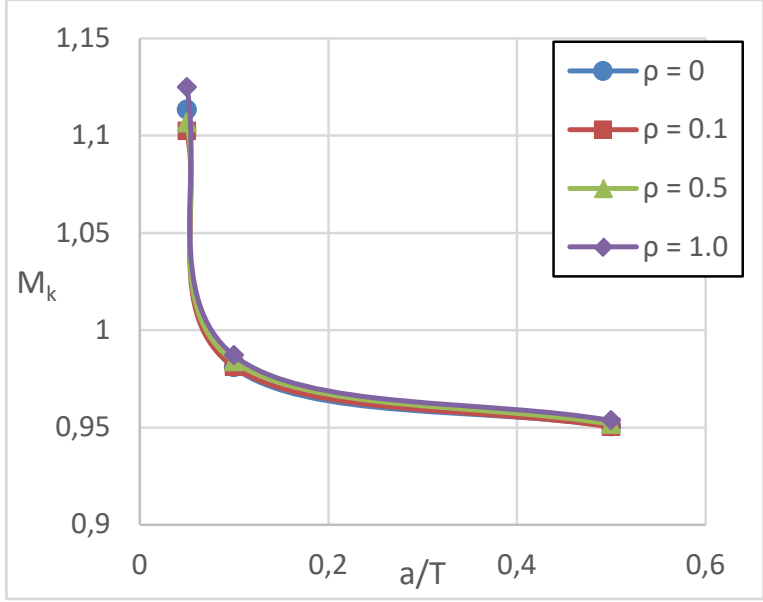

b) 


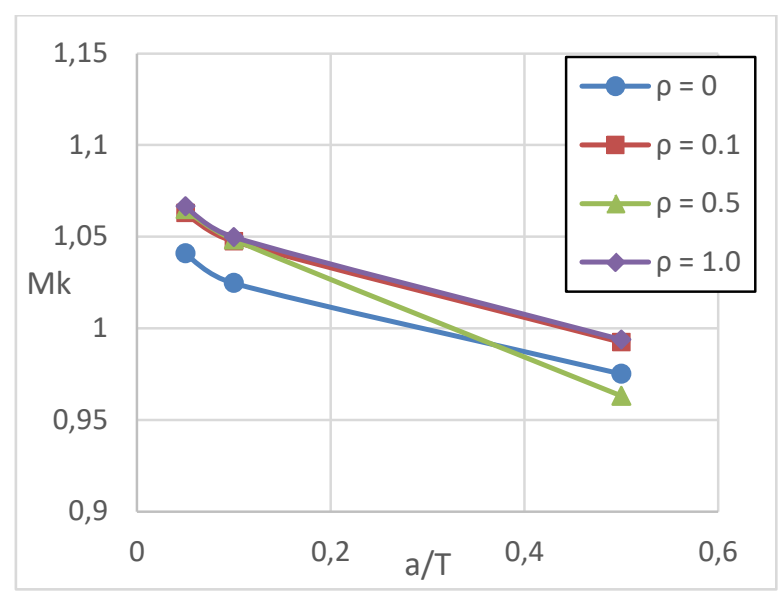

c)

Figure 9. $M_{k, a}$ values for deepest point of crack under four point bend loading: a) $\mathrm{a} / \mathrm{c}=1.0 ; \mathrm{b}$ ) $\mathrm{a} / \mathrm{c}=0.5 ; \mathrm{c}$ ) $\mathrm{a} / \mathrm{c}=0.25$.

The weld toe radius has a negligible effect on the $\mathrm{M}_{\mathrm{k}, \mathrm{a}}$ values, and therefore the stress intensity factor at the deepest point of the crack.

\section{$4 \quad$ Fatigue Life prediction}

\section{1 $M_{k}$ factor solutions}

With the results obtained in the above section, the $M_{k}$ factors obtained can be curve fitted into solutions, as a function of $a / T$ ratios, expressed in the form of a power law (Eqn. 2). For this current fatigue life prediction, a crack aspect ratio, $a / c=0.5$, will be used, with only bending load considered.

The $M_{k}$ factor solutions follow the format of the following equation:

$$
M_{k}=x\left(\frac{a}{T}\right)^{y}+z
$$

where the coefficients $x, y$ and $z$ can be found in Table 7 .

Table 7. $\mathrm{M}_{\mathrm{k}}$ coefficients $x, y$ and $z$ for $a / c=0.5$

\begin{tabular}{|c|c|c|c|c|}
\hline \multirow{2}{*}{ Loading } & \multirow{2}{*}{ Radius, $\boldsymbol{\rho}$} & \multicolumn{3}{|c|}{$\mathbf{M}_{\mathbf{k}, \mathbf{c}}$} \\
\cline { 3 - 5 } & & $\mathbf{x}$ & $\mathbf{y}$ & $\mathbf{Z}$ \\
\hline \multirow{2}{*}{$\mathbf{M}_{\mathbf{k}, \mathbf{c}}$} & 0.0 & 0.4141 & -0.3088 & 0.6416 \\
\cline { 2 - 5 } & 1.0 & 0.1388 & -0.4266 & 0.9408 \\
\hline \multirow{2}{*}{$\mathbf{M}_{\mathbf{k}, \mathbf{a}}$} & 0.0 & 0.0001235 & -2.399 & 0.9498 \\
\cline { 2 - 5 } & 1.0 & 0.0001602 & -2.329 & 0.9528 \\
\hline
\end{tabular}

\subsection{Fatigue life prediction}

For the fatigue life prediction, the material was modeled following X65 steel, similar to a previous experiment [10]. The yield strength and ultimate tensile strength of the base material was obtained via relation to hardness $\left(\sigma_{\mathrm{Y}}=550\right.$ and UTS $\left.=633 \mathrm{MPa}\right)$. The following fatigue law constants were used: design values of $C=5.21 \times$ $10^{-13}$ and $m=3$ as given in the BS 7910 standard [1]. Small semi-elliptical surface cracks of initial crack depth $(a=0.1 \mathrm{~mm})$ and aspect ratio $(a / c=0.5)$ were used. The SIFs of plain plates obtained by Newman and Raju [12] are used in the analysis. The locations of each crack initiation sites were reported in Pang et al [10]. The loading type applied was bending, at a load of $320 \mathrm{MPa}$.
The fatigue life prediction is conducted through a $\mathrm{C}++$ program developed called Fatigue Crack Growth Analysis (FCGA) software. This was developed to evaluate the fatigue life of welded structures with many weld toe semi-elliptical surface cracks (any number of sites and different crack sizes). The FCGA software can accommodate fatigue threshold constants, crack closure based Paris Laws. $\mathrm{M}_{\mathrm{k}, \mathrm{c}}$ and $\mathrm{M}_{\mathrm{k}, \mathrm{a}}$ factors can be curvefitted for FCGA entry format. An illustration of the FCGA software results is shown in Figure 10. The multiple weld toe cracks coalesce and emerge as a single fatigue crack leading to final crack size as the four-point bending fatigue test was stopped when the crack depth exceeds $70 \%$ of the plate thickness.

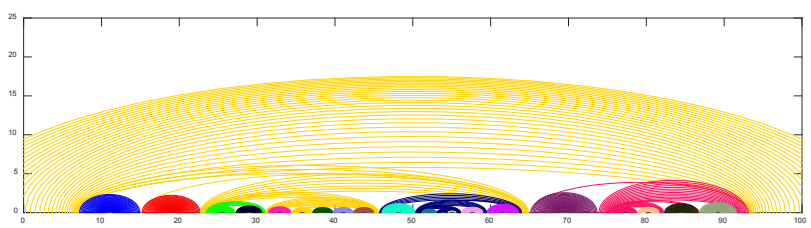

Figure 10. Many crack initiation sites from weld toe

The result of the fatigue life prediction is shown in Table 8, for the sharp weld toe versus the weld toe with a radius of $1.0 \mathrm{~mm}$. The percentage difference in predicted fatigue life is $67 \%$ longer with respect to a sharp weld toe condition compared to the case with a $1.0 \mathrm{~mm}$ weld toe radius.

Table 8. Fatigue life prediction results

\begin{tabular}{|c|c|}
\hline Radius, $\boldsymbol{\rho}(\mathbf{m m})$ & Fatigue Life, (cycles) \\
\hline 0.0 & 123,500 \\
\hline 1.0 & 206,000 \\
\hline$\%$ diff & $67 \%$ \\
\hline
\end{tabular}

The results show that the weld toe radius has a significant effect on the predicted fatigue life of the test specimen. Life prediction using $\mathrm{M}_{\mathrm{k}}$ factors from sharp weld toe models gives conservative predict fatigue life. On-going studies are in progress for weld-toe grinding radius effect on $\mathrm{Mk}$ factors and predicted fatigue lives.

The actual four-point bend fatigue test life was 377,921 cycles. This indicates that the overall total fatigue life from the fatigue test result is longer. Hence, crack initiation or early crack growth effects may be needed to model the total fatigue life, crack initiation and propagation life of the test specimen.

\section{Conclusion}

The effect of weld toe radius on the fatigue behavior of a cut-out butt weld specimen was investigated. Four weld toe radii and two modes of loading were reported.

From this study, the weld toe radius of $1.0 \mathrm{~mm}$ can reduce the stress intensity factor at the weld toe for small cracks $(a / T=0.05)$. The decrease in $\mathrm{M}_{\mathrm{k}, \mathrm{c}}$ factor was $16.3 \%$ in the case of $a / c=1, a / T=0.05$ for tensile load, and $18.9 \%$ in the case of $a / c=0.25, a / T=0.05$ for bending. 
The results of the fatigue life prediction show that the weld toe radius has a significant effect on the predicted fatigue life of the butt weld joint. The fatigue life with the radius of $1.0 \mathrm{~mm}$ increases the fatigue life by $67 \%$ compared to the case with a sharp toe with zero toe radius. The fatigue life prediction employs the FCGA software which is able to model the multiple weld toe cracks found in the test result. The weld toe radius dependent $M_{k, c}$ factor reported in this work provide useful data and insights on how to incorporate weld toe radius effects in fatigue life prediction applications for welded joints.

\section{References}

1. British Standards Institution, BS 7910:2013. (2013)

2. S. Tanaka, T. Kawahara, and H. Okada, Mar. Struct., 39, 315-334, (2014)

3. P. C. Paris and F. Erdogan, J. Fluids Eng., 85, 528, (1963)

4. W. He, J. Liu, and D. Xie, Mar. Struct., 35, 45-69, (2014)

5. S. J. Maddox, Int. J. Fract., 11, 2, 221-243, (1975)

6. X. Niu and G. Glinka, Int. J. Fract., 40, 255, (1989)

7. F. P. Brennan, W. D. Dover, R. F. Karé, and A. K. Hellier, Int. J. Fatigue, 21, 1051-1062, (1999)

8. Y. H. Zhang, S. J. Maddox, and G. R. Razmjoo, 36134, 525-533, (2002)

9. D. Bowness and M. M. K. Lee, Int. J. Fatigue, 22, 369-387, (2000)

10. J. H. L. Pang, H. J. Hoh, K. S. Tsang, J. Low, S. C. Kong, and W. G. Yuan, Int. J. Fatigue, 94, 158-165, (2017)

11. J. H. L. Pang, K. S. Tsang, and H. J. Hoh, Mar. Struct., 48, 1-14, (2016)

12. J. C. Newman and I. S. Raju, Eng. Fract. Mech., 15, 185-192, (1981) 